\title{
HIV Prevention Among Young Women in South Africa: Understanding Multiple Layers of Risk
}

\author{
Christina Psaros ${ }^{1,2}$ (1) Cecilia Milford ${ }^{3} \cdot$ Jennifer A. Smit $^{3,4} \cdot$ Letitia Greener $^{3}$. \\ Nzwakie Mosery $^{3} \cdot$ Lynn T. Matthews $^{2,5} \cdot$ Abigail Harrison $^{6} \cdot$ Janna R. Gordon $^{7}$ • \\ Matthew Mimiaga ${ }^{8,9,10,11,12} \cdot$ David R. Bangsberg ${ }^{13} \cdot$ Steven A. Safren $^{14}$
}

Received: 4 June 2014 / Revised: 21 July 2017 / Accepted: 9 August 2017 / Published online: 13 November 2017

(C) Springer Science+Business Media, LLC 2017

\begin{abstract}
Despite concerted prevention efforts, young South African women remain at the epicenter of the HIV epidemic. Although these women have grown up in a community powerfully affected by HIV, systematic investigation into how this "second generation" of HIV-affected youth navigates HIV risk is lacking. This study qualitatively explored a complex interplay of factors influencing HIV risk among young pregnant women in KwaZulu-Natal, South Africa. We conducted in-depth interviews with 35 pregnant women (22 HIV-uninfected and $13 \mathrm{HIV}$ infected) aged 18-21, 18 healthcare providers, and focus groups with 19 community stakeholders. Among the young women, HIV knowledge was high, and many reported taking some action to prevent pregnancy or HIV; however, these efforts were not routinely implemented. Themes related to HIV acquisition risk from all participants were organized using a socioecological framework and revolved around individual and developmental experiences
\end{abstract}

Christina Psaros

cpsaros@mgh.harvard.edu

1 Behavioral Medicine Program, Department of Psychiatry, Massachusetts General Hospital, One Bowdoin Square, 7th Floor, Boston, MA 02114, USA

2 Department of Psychiatry, Harvard Medical School, Boston, MA, USA

3 MatCH Research Unit (Maternal, Adolescent, and Child Health Research Unit), Department of Obstetrics and Gynecology, Faculty of Health Sciences, University of the Witwatersrand, Durban, South Africa

4 School of Health Sciences, College of Health Sciences, University of KwaZulu-Natal, Durban, South Africa

5 Center for Global Health and Division of Infectious Disease, Massachusetts General Hospital, Boston, MA, USA

6 Department of Behavioral and Social Sciences and International Health Institute, Brown University School of Public Health, Providence, RI, USA (personal experience with HIV, perceived invincibility), family barriers (lack of adult supervision, pressure to leave school), relational barriers (lack of disclosure and partner communication, "burn out" around attempts to discuss condom use with partners, overdependence on partners), community-level barriers (township environment, lack of structured activities), and social barriers (poverty, HIV-related stigma). Some novel concepts emerged from the data, including an understanding of how overdependence on the romantic relationship may develop. Current HIV prevention efforts, including traditional HIV counseling and testing, condom distribution, and biomedical agents for HIV prevention, are unlikely to be effective without a broader, ecological upto-date understanding of the evolving, intertwined, and complex constellation of factors that drive HIV risk behavior in this highrisk population.

7 San Diego Joint Doctoral Program in Clinical Psychology, San Diego State University/University of California, San Diego, CA, USA

8 The Fenway Institute at Fenway Health, Boston, MA, USA

9 Department of Behavioral and Social Health Sciences and Epidemiology, School of Public Health, Brown University, Providence, RI, USA

10 Department of Psychiatry and Human Behavior, Alpert Medical School, Brown University, Providence, RI, USA

11 Institute for Community Health Promotion, Brown University, Providence, RI, USA

12 Department of Epidemiology, Harvard T. H. Chan School of Public Health, Boston, MA, USA

13 School of Public Health, Oregon Health \& Science UniversityPortland State University, Portland, OR, USA

14 Department of Psychology, University of Miami, Miami, FL, USA 
Keywords HIV risk · Pregnancy · Young women ·

Interventions $\cdot$ South Africa

\section{Introduction}

Due to intensive public health prevention efforts, HIV incidence worldwide has fallen dramatically in the last decade (UNAIDS, 2013). Despite this success, nations such as South Africa (SA) continue to be heavily burdened by HIV disease. In SA, an estimated 6.4 million individuals were living with HIV in 2012 (Shisana et al., 2014), comprising 17\% of all HIV-infected persons worldwide (UNAIDS, 2013). Young women in this region are at particular risk of HIV; nearly one quarter of all new HIV infections in SA occur among young women ages 15-24 (Shisana et al., 2014). Accordingly, these young women may be among the most at-risk individuals for HIV in the world.

While the epidemic in SA is generalized, young South Africans are at disproportionate risk of acquiring HIV (Shisana et al., 2014). Community and relational factors that may increase their risk include inadequate social capital (Gregson et al., 2011) and inconsistent condom use (Pettifor et al., 2005), while individual-level factors may include poor self-esteem (Wild, Flisher, Bhana, \& Lombard, 2004), substance abuse (Browne \& Wechsberg, 2010), and psychiatric illness (Pitpitan et al., 2013). Adolescents facing disruption of their primary family unit due to HIV may also experience poverty, abuse, or neglect, all of which have been associated with greater HIV risk (Jewkes, Dunkle, Nduna, \& Shai, 2010; Kalichman et al., 2006; Operario, Pettifor, Cluver, MacPhail, \& Rees, 2007). HIV risk factors specific to women include gendered social norms (Jewkes \& Morrell, 2010), coerced sexual activity (Hoffman, O'Sullivan, Harrison, Dolezal, \& Monroe-Wise, 2006), overlapping sexual partnerships (Chen et al., 2007), early sexual debut (Pettifor, O'Brien, MacPhail, Miller, $\&$ Rees, 2009), relationships with older men (Pettifor et al., 2005), transactional sex (Chen et al., 2007), and certain culturally based vaginal practices (Hilber et al., 2010). There does not appear to be a single, unifying reason for the incredibly high incidence and prevalence of HIV among young women in SA.

Despite abundant intervention research in the past decade (Harrison, Newell, Imrie, \& Hoddinott, 2010; Napierala Mavedzenge, Doyle, \& Ross, 2011), extant prevention efforts have not appreciably reduced HIV prevalence in young South African women age 15-24. A recent systematic review (Napierala Mavedzenge et al., 2011) found that school-based interventions reduce HIV risk behavior but have little effect on biological outcomes such as pregnancy and HIV incidence, while interventions delivered in health facilities increase use of health services but negligibly impact risk behaviors and biological outcomes. Community-based interventions designed to increase knowledge and promote health behavior change have produced weak results or have not been sufficiently developed for widespread implementation (Napierala
Mavedzenge et al., 2011). Recent surveys suggest that condom use among young South Africans may be decreasing, and that condom use is inconsistent at best (Chirinda \& Peltzer, 2014; Dietrich et al., 2013; Nyembezi et al., 2014; Toska, Cluver, Boyes, Pantelic, \& Kuo, 2015). Furthermore, between 2008 and 2012, condom use at last sex declined nearly $20 \%$ among South African females 15-24 years of age, while multiple partnerships increased (Shisana et al., 2014). Ultimately, data reflect these challenges: HIV prevalence among antenatal South African women aged 15-24 was $21.7 \%$ in 2008 and $20.5 \%$ in 2011 (National Department of Health, 2011), indicating little improvement despite modest success in intervention research. These data highlight the need for further research to elucidate why this population continues to be at such risk.

Young adults living in SA have grown up in communities heavily impacted by HIV/AIDS, becoming the "second generation" of individuals to inhabit a society shaped by the HIV epidemic. One might hypothesize that a "second generation" of individuals at high risk of HIV would show a decrease in risk behaviors in the context of witnessing family and social losses due to the generalized epidemic. However, this "second-generation" population also experiences multiple individual and developmental, family, relational, community/peer, and societal factors that may influence adolescent social development and attitudes toward sexuality, possibly engendering a generation of adolescents more vulnerable to factors that predispose one to HIV than the previous generation; these young women remain persistently at risk of HIV despite living in a high-prevalence environment and exposure to multiple prevention initiatives. While existing literature clearly documents single risk factor for HIV, the mechanism by which these multiple risk factors may interact is, to date, largely underexplored. A current, comprehensive picture of the context in which HIV risk occurs among this high-risk group is essential and will be particularly valuable as biomedical prevention strategies become more widely available (oral pre-exposure prophylaxis [PrEP] in the form of tenofovir disoproxil fumarate and emtricitabine was approved for use in South Africa in November 2015) (Registrar of Medicines, 2015), and their effectiveness for African women is debated (Baeten et al., 2016; Kapiga et al., 2016; Marazzo et al., 2013; Van Damme et al., 2012). Thus, this study used qualitative methods to explore and identify factors thought to influence HIV risk behavior in a second generation of young women in KwaZulu-Natal, SA, in order to generate new hypotheses related to factors that may influence risk, and their interactions.

\section{Method}

\section{Participants}

We recruited 35 pregnant women (referred to as index participants; 22 of whom self-reported being HIV uninfected, 13 of 
whom reported being HIV infected) receiving antenatal care from a District Hospital in a township in eThekwini District, KwaZulu-Natal Province, as part of a free-standing qualitative study. South African women experience high rates of pregnancy, which puts them at risk of HIV via unprotected sexual intercourse. Approximately $15 \%$ of South African women aged 15-19 and 53\% of young women aged 20-24 reported having ever been pregnant in a nationally representative survey (Pettifor et al., 2004). Pregnancy has been associated prospectively with increased risk of HIV acquisition, with studies finding that HIV risk doubles during pregnancy (Mugo et al., 2011). Clients were purposively sampled based on HIV and pregnancy status and invited to participate in one-time, semi-structured, in-depth individual interviews between June 2011 and March 2012. We sampled pregnant women given their elevated risk of HIV as a result of unprotected sexual intercourse. Other inclusion criteria were (1) age 18-21 years; (2) willing to report known HIV status; (3) receiving antenatal care at a public healthcare facility; (4) primary language English or isiZulu; and able to give (5) written informed consent. We also conducted individual in-depth interviews with 18 healthcare providers (key informants) and two focus-group discussions (one male and one female) with 19 active community stakeholders to collect additional data on factors influencing HIV risk in this population. Inclusion criteria for the healthcare workers were (1) employment as a healthcare worker in an HIV testing center, antiretroviral therapy (ART) clinic, or other healthcare setting (e.g., antenatal clinic staff, prevention of maternal to child transmission clinic staff, etc.); (2) primary language English or isiZulu; and (3) able to give written informed consent. Inclusion criteria for the community stakeholders were (1) documented membership in a community organization including, but not limited to: (a) a church or other religious organization, (b) community advisory board (CAB); (2) primary language English or isiZulu; and (3) able to give informed consent. All study procedures were approved by the University of the Witwatersrand Health and the Human Research Ethics Committee and Partners Healthcare in Boston, MA. Permission to conduct the study was also provided by the KwaZulu-Natal Department of Health, the recruitment site, and the Municipality Ward Counselor. After a complete description of the study was provided to the participants, study staff obtained written informed consent.

\section{Measures}

A semi-structured interview guide, developed using guidelines articulated by Huberman and Miles (2002), was used to collect data. Topics included attitudes toward HIV, fertility desire, sexual practices and nature of partnerships, early childhood experiences, community involvement and social relationships, and substance use.

The interview guide was piloted with the first 5 index participants to assess its clarity and content. Specifically, in order to obtain more in-depth responses, we included additional queries about participants' family life, relationships, and sexual behavior. Questions were neutral and open-ended in order to minimize the risk of biasing participants' responses and to allow for novel themes to emerge. Sample questions and probes are provided in Tables 4 and 5. Participants were paid ZAR 70 (approximately $\$ 10$ at the time data were collected) for their travel expenses and time. Index participant interviews and key informant interviews both took place at the district hospital where recruitment occurred and lasted approximately 90 and $60 \mathrm{~min}$, respectively. Focus group discussions took place at a community center and lasted approximately $120 \mathrm{~min}$. Interviews were administered by trained, bilingual (isiZulu and English) racially concordant, female interviewers. Data presented here are related to the themes that emerged from the participants' experiences with HIV prevention efforts.

\section{Analyses}

Interviews and focus group discussions were digitally recorded, translated, and transcribed. Using a grounded theory approach, content analyses were conducted using NVivo 10 software (2012) to uncover themes exploring social processes and concepts related to HIV prevention (Strauss \& Corbin, 1998). While we had hypotheses as to what factors may influence HIV risk in this population based on existing literature, we were also interested in understanding how these factors may function together (along with more novel or less studied factors). We were also interested in positing a comprehensive model allowing for development of hypotheses around the influence of multiple risk factors. Thus, we used a ground theory approach for the analyses. This entailed an iterative multistep process performed by the authors (CP, CM, LG, LTM, AH, JS, SAS) using the techniques described by Miles and Huberman (1984). Socioecological models have been used to explain and capture the complex array of factors influencing individual behavior, including HIV risk behavior, and take into account the aggregate role of each of these factors (Stokols, 1996). Use of socioecological models to understand data may also more easily inform multidisciplinary interventions (Stokols, 1996). Thus, we organize our findings within a socioecological framework proposed by DiClemente, Salazar, Crosby, and Rosenthal (2005) to understand the acquisition of sexually transmitted infections among adolescents.

Consistent with the model, we organize our data according to identified spheres of influence on HIV risk: individual/developmental, family, relational, community/peers, and societal. Coding was performed to structure data into categories. Themes were then reexamined, and major and minor themes within each conceptual area were identified; messages across all three groups of participants were extracted and highlighted. After initially coding approximately $25 \%$ of the same interviews to ensure consistent use of the codebook, three coders (CP, CM, LG) analyzed the data independently. Additionally, results from each phase of analyses were compared, and discrepancies were discussed between the coders until a resolution was reached. An audit trail of 
coding templates and discussions about the data and computerized coding were kept. We referred to this audit trail to resolve discrepancies, and compared computerized coding to raw data. To check for validity, at each phase of the analyses the authors (CP, CM, LG, LTM, AH, JS, SAS, DRB) discussed findings to assure that the interpretation of data was not being influenced by preconceived theories. Review of the qualitative process was provided by $\mathrm{AH}$ and JS, while review of HIV-related content was provided by $\mathrm{JS}, \mathrm{AH}, \mathrm{SAS}$, and DRB.

\section{Results}

Sociodemographic data for participants are presented in Tables 1, 2, and 3; none of the pregnancies were planned. As noted above, data were organized across broad domains thought to influence HIV risk based on a socioecological framework, including individual, family, relational, community/peers, and societal factors. We started by describing the individual contributors to HIV risk behavior and then move to the broadest level of influence, societal. We attempted to identify differences between the HIV-infected and uninfected index participants by comparing data bet- ween these two groups; however, distinctions in HIV knowledge, experiences, and behavior did not emerge. Because many of our findings transcend multiple categories, we attempted to select the category with the best fit and highlight synergies between categories whenever possible, consistent with the goals of this study. Figure 1 demonstrates the ways in which each domain interacts with the others.

\section{Individual and Developmental: Personal Experience with HIV, Perceived Adolescent Invincibility, and Maturity}

Most index participants described personal experience with HIV, independent of their own serostatus. These experiences often involved a family member, many of whom had died of HIV-related consequences. While orphanhood will be discussed in greater detail below in the context of familial risk factors for HIV acquisition, index participants explained their personal emotional reactions to orphanhood as a result of HIV.

Table 1 Demographic characteristics of index participants

\begin{tabular}{|c|c|c|}
\hline \multirow[t]{2}{*}{ Variable } & \multicolumn{2}{|c|}{ Participant sample $(N=35)$} \\
\hline & $n$ & $\%$ \\
\hline \multicolumn{3}{|l|}{ Age (in years) } \\
\hline$M=19.3$ & - & - \\
\hline$S D=1.1$ & - & - \\
\hline \multicolumn{3}{|l|}{ Race/ethnicity } \\
\hline Black South African & 35 & 100.0 \\
\hline \multicolumn{3}{|l|}{ HIV serostatus } \\
\hline HIV infected & 13 & 37.1 \\
\hline \multicolumn{3}{|l|}{ Education } \\
\hline Currently enrolled in or completed secondary high school & 21 & 60.0 \\
\hline Enrolled/completed school and HIV infected & 5 & 14.3 \\
\hline On leave from or terminated schooling before completing secondary/high school & 14 & 40.0 \\
\hline On leave/terminated and HIV infected & 8 & 22.8 \\
\hline \multicolumn{3}{|l|}{ Relationship characteristics } \\
\hline Pregnancy was unplanned & 35 & 100.0 \\
\hline Father of baby is current partner & 29 & 82.9 \\
\hline Involved in concurrent partnerships ${ }^{\mathrm{a}}$ & 0 & 0.0 \\
\hline \multicolumn{3}{|l|}{ Age of partner/father of baby ${ }^{a}$} \\
\hline$M=24.8$ & - & - \\
\hline$S D=3.9$ & - & - \\
\hline \multicolumn{3}{|l|}{ HIV serostatus of partner/father of baby } \\
\hline HIV positive & 11 & 31.4 \\
\hline HIV negative & 16 & 45.7 \\
\hline HIV status unknown & 8 & 22.8 \\
\hline
\end{tabular}

${ }^{a}$ Information was not available for all participants 
Table 2 Demographic characteristics of key informants (healthcare professionals)

\begin{tabular}{lll}
\hline Variable & \multicolumn{2}{l}{ Participant sample $(N=18)$} \\
\cline { 2 - 3 } & $n$ & $\%$ \\
\hline Age (in years) ${ }^{\mathrm{a}}$ & & - \\
$M=38.9$ & - & - \\
$S D=12.5$ & - & 27.8 \\
Gender & 5 & 72.2 \\
Male & 13 & \\
Female & & 94.4 \\
Race/ethnicity & 17 & 5.6 \\
Black South African & 1 & \\
Indian & & 27.8 \\
Occupation & 5 & 44.4 \\
Counselor & 8 & 16.7 \\
Nurse & 3 & 11.1 \\
Student Nurse & 2 & \\
Other & & 55.5 \\
Type of clinic & 10 & 27.8 \\
ARV & 5 & 16.7 \\
Antenatal & 3 & \\
PMTCT & & \\
\hline
\end{tabular}

${ }^{a}$ Information was not available for one participant

I do not have a mother today because of it [HIV]; it affected me a lot that way. (Index participant; HIV-uninfected; 18 years)

My parents are infected. I was hurt when I first found out, to see my mother losing weight, having things that grew in her body. (Index participant; HIV-uninfected; 20 years)

Despite this, and a robust knowledge of HIV, all participants described a sense of relative invincibility among young women, a sense that "HIV can't happen to me," and faced additional barriers to HIV prevention efforts.

Young people do not listen. Most of them believe in seeing as believing, "I will see when I have it that this is truthfully real.” (Index participant; HIV-uninfected; 19 years)

At that time I was like, I will never get HIV; I can't get HIV. I am too young for HIV. Most young girls are promiscuous. They think they are invincible. (Index participant; HIV-infected; 20 years)

Some, some tell themselves that "Not me, it will never happen to me. I will do like this and it will never happen to me; it happened to so and so because she wanted it, it will not happen to me." (Professional Nurse; female; 58 years)
Table 3 Demographic characteristics of focus group participants (community stakeholders)

\begin{tabular}{lll}
\hline Variable & \multicolumn{2}{l}{ Participant sample $(N=19)$} \\
\cline { 2 - 3 } & $n$ & $\%$ \\
\hline Age (in years) & & - \\
$M=41.2$ & - & - \\
$S D=6.5$ & & \\
Gender & 8 & 42.1 \\
Male & 11 & 57.9 \\
Female & & \\
Race/ethnicity & 19 & 100 \\
Black South African & & \\
Education & 8 & 42.1 \\
Less than grade 12 & 7 & 36.8 \\
Completed grade 12 & 4 & 21.1 \\
Post-secondary & & \\
Role in community & 6 & 31.6 \\
CAB member & 8 & 42.1 \\
Caregiver & 2 & 10.5 \\
Volunteer & 3 & 15.8 \\
Other & & \\
\hline
\end{tabular}

Several index participants and a few healthcare providers indicated that HIV was no longer something to fear, and the consequences of infection, no longer dire.

I think they do not fear it because people continue to live with it. You find people claiming that HIV is like having flu. (Index participant; HIV-uninfected; 19 years)

You see, now people with HIV are much better than us. They are taken care of in a lot of places; they are the most important people and the pills are now available. It is not easy for you to just die like that anymore. I would not have a problem if I get infected. (Index participant; HIVuninfected; 20 years)

Almost all healthcare providers cited high HIV prevalence (a community issue) as a barrier to HIV prevention efforts whereby young women engaged in normal adolescent sexual behavior, but were more likely to acquire HIV given the high prevalence in the community. Thus, individual behavior that occurs in community with a high HIV burden confers significant risk. When asked about why young women do not protect themselves from HIV, one healthcare provider noted:

It think it's their maturity. I don't think that they really think through what they are doing at that moment. They just get caught up in their adolescent world, where they want to be deviant with their parents, or they want to do as they please. 


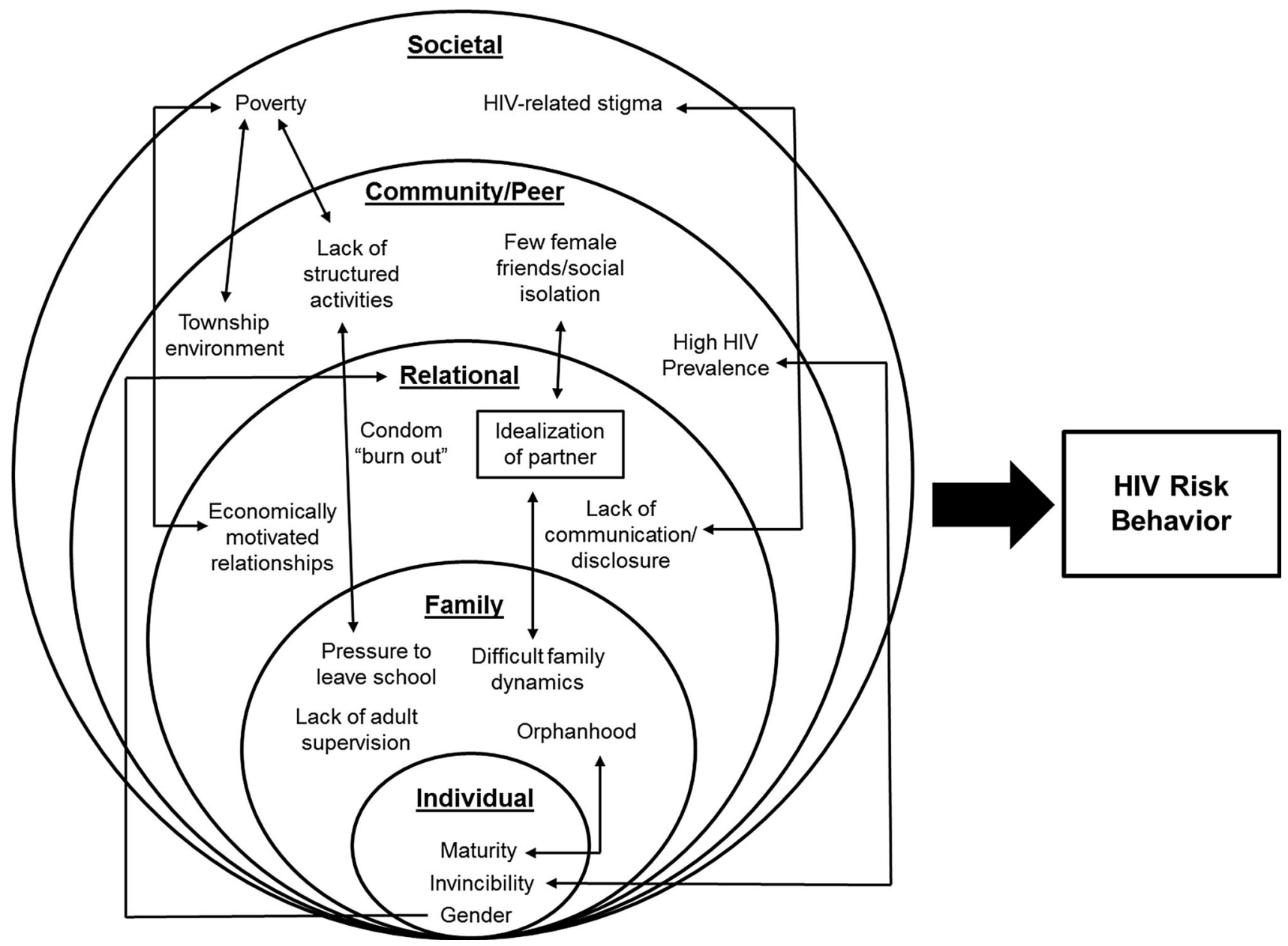

Fig. 1 Proposed model of HIV risk behavior

When you're an adolescent, your mindset is totally different. (Professional Nurse; female; 38 years)

Another healthcare provider, who was similar to index participants with respect to age, remarked:

Sometimes it is because you like the guy and whatever you learned just switches off, like you can go to church on Sunday and they would teach you different things and you could see the like of living life greatly, but once you are out of church, once your friends come and say "Let us go to this party, there is this thing going on," it just switches off like that. (Student Nurse; female; 21 years)

Several index participants described similar processes that influenced their decisions around protecting themselves from HIV and pregnancy, in addition to other challenges (such as substance use), which are elaborated on below.

You tell people to use condoms, but once they are drunk, they forget about all of that. Most of the time, a lot of men like to say "Hey, I don't want a plastic, I want flesh-to- flesh," especially when a guy sees that you are so drunk you cannot even see straight, and he would say "Why should I use a condom, she cannot even see what I am doing." (Index participant; HIV-uninfected; 20 years)

Furthermore, these adolescent factors were cited as reasons why HIV prevention strategies to date have not fully succeeded in curbing the HIV epidemic. When asked how healthcare providers and the HIV prevention community could improve upon efforts to help young women remain HIV negative, none of the participants could identify new strategies. Index participants and healthcare providers alike noted that adolescents are disinclined to engage in HIV risk reduction strategies despite adequate knowledge and education regarding HIV.

You can do all that [HIV prevention work], but still, in the end, you might do that, and a person would say "Fine, I agree," but at the end of the day, they will go back and do the same thing. We do not want to listen, that is our problem. We do not listen, you see. (Index participant; HIVuninfected; 20 years) 
I think everything has [been] done for me. Because there [are] adverts on TV, there are pamphlets all over the place, there are clinics. Even in radio, there is HIV. I think enough has been said about HIV; there is nothing much more you can say that will make a difference to people... I just don't see anything, because you're going to tell them to use condoms and they will tell you "No," they will just tell you themselves that "We know that." Tell them to do this, [they'll say] "No, we know that, tell us something we don't know," you see. The youth is like that, what can you say? (Student Nurse, female, 22 years)

\section{Family: Orphanhood, Difficult Relationships with Adult Caregivers, and Absence of Adult Role Models}

Orphanhood was routinely cited by all participants as another challenge facing this community. The consequences of losing a parent were described as particularly profound when another adult could not be identified to fulfill the parent role. Many participants described parents as role models and educators regarding sexual health; thus, orphans often passed into adolescence without this guidance. There were also multiple factors that could negatively impact a parent's role, including assuming the responsibility of caring for a young woman unwillingly, as well as cultural norms around speaking to young people about sexual activity.

It is difficult for them, especially if they don't have a grown up person who gives them guid[ance] and tells them that what you are doing is right or is wrong. (Index participant; HIV-infected; 20 years)

There is this thing of not familiarizing yourself with sex. It [is] very difficult for a female parent to talk to her female child, much more if it is a female child taken care of by a male parent without a female parent, because of parents not staying together. At the end this child does not hear things from parents, but hears things from other people in her age group. (Administrator; male; 33 years)

Community members and healthcare providers expressed frustration around the lack of parents or caregivers to take responsibility for raising young women equipped with skills and knowledge needed to manage the HIV epidemic, and this sentiment was also described by some of the index participants.

The kids are left to their own devices a lot. They are left alone and there is no supervision, and then when the cat's away the mice will play. So they want to experiment, they want to see, they want to experience things other people have been talking about. (Professional Nurse; female; 38 years)

And the fact that I have never had a person who would tell me that it is wrong to have sex at a certain age, or that if I am going to date someone, not to date someone who [has] reached the point of sexuality. So not having a person to guide me the path of from the start of the periods, have a person who would say to me "Okay, since you are starting your periods, you will be able to get pregnant and have children"; I have never had someone like that, I had to learn that by myself. (Index participant; HIVuninfected; 19 years)

I am blaming my parent because maybe if she was there for me, all of this wouldn't have happened. If you talk to a child, she will see that "No, my mother, we struggling here at home, we can't do that" but if your parent disappears, just vanishes from your eyes, and [you] don't know who to ask, and even if you trying to ask someone, she can't be able to give it to because of some other reasons, you just see your life not existing. (Index participant; HIVinfected; 21 years)

A few index participants described their most important relationships as the ones with an adult female caregiver; however, when asked to elaborate on the nature of these relationships, participants often described relationships that seemed more consistent with friendship than with the guidance, encouragement and education of a parent figure. When describing her relationship with her mother, one participant noted:

Because we share everything. Anything that bothers me or anything that is happening in my life, I talk to her. She also talks to me, because we both do not have friends that we trust. (Index participant; HIV-uninfected, 18 years)

\section{Relational: Idealization of the Romantic Relationship, Economically Motivated Relationships, Lack of Communication, and Condom "Burn-Out"}

As described above and highlighted again in the peer and community section below, lack of peer and family support resulted in many index participants being unable to identify an individual aside from their partner who was important to them. Thus, romantic partners were one of the most important relationships in the index participants' lives. Coupled with little to no family, no important activities (discussed below), and significant poverty, the importance of maintaining this partnered relationship is clear. Many participants appeared to idealize their romantic partners; in some cases, index participants stayed with partners in the presence of knowledge of infidelity.

Yes I met him when he really liked girls and I cannot change that, but he has limited them now. He used to do it publicly, but now he hides it from me. I do not know whether he has sex with them or not, but I know he has 
other partners. (Index participant; HIV-uninfected; 20 years)

When asked whether she was worried about HIV upon learning she was pregnant, one participant reported:

I thought about it, but I sometimes would take it off my mind and say I trust this man; he will not infect me with HIV like that. Ihad that trust in him that he does not have HIV. (Index participant; HIV-uninfected; 20 years)

In addition to describing romantic partners as their primary, or even sole, source of emotional support, some women described economic incentives related to sexual or romantic partnerships, such as gaining access to food, clothing, and cell phones. Economically motivated relationships are discussed further in the context of widespread poverty in societal factors below.

Participants described numerous partnership dynamics contributing to HIV risk. All index participants described knowledge of basic HIV prevention strategies, including the importance of using condoms and limiting the number of sexual partners. However, some of this knowledge was not applicable or relevant to their circumstances. Confusion around the possibility of serodiscordant statuses between partners created some confusion about risk as illustrated by the following participant:

It's not difficult, it's just that I did not know that if I am negative, he can be positive. I thought if I am negative, he is also negative; I didn't know that even if you do not use condoms, one of you could be positive and the other one be negative. He does not believe that, he just says there is no such thing, it's impossible that you could be having unprotected sex and have one partner negative and the other one positive, and I would say to him he must go to someone who deals with HIV and let them tell him properly so that you understand. (Index participant; HIV uninfected; 20 years)

Most index participants made efforts to talk with their partners about HIV, but in many cases, this was after unprotected sexual activity had occurred. When asked about her partner's status one participant noted:

No, I only knew it after we had slept. I went and checked. (Index participant; HIV-uninfected; 19 years)

When asked whether they had spoken with a partner about HIV, other participants reported:

No, we have never talked about it, the only thing he says... is that I should get tested for HIV early so that if we are positive, we can protect the baby early. He has never been tested before. (Index participant; HIV-uninfected; 20 years)

When I started talking to him about HIV is when he infected me with STIs. I went to the clinic, he could not see anything on him that he had infected me with, and I went to the clinic, that is when we started talking about HIV. (Index participant; HIV-uninfected; 18 years)

Almost half of index participants described efforts to use condoms, but numerous barriers precluded successful routine use, the majority of which were related to male partners' preferences.

Oh, I've tried to tell my boyfriend that we must use a condom. But he refuses it, he said he never used a condom in his life and he also said it means he is not going to have sex with me if I can't sleep without a condom. Then it was obvious that I want, he said, maybe I want us to break up, then I said 'no,' then we had sex without using a condom. (Index participant; HIV-infected; 18 years)

Repeated unsuccessful attempts at condom negotiation with partners resulted in a "burn-out" among some index participants. The need for condoms was seen as further diminished after unprotected sex had occurred.

He has never asked me [to use a condom] but I ask him sometimes and I fail even after asking him...[he says] "You are asking me to use a condom, something that we have never used even from the beginning. Why, are you dating or what?" He asks me silly questions. I end up being tired of asking for that condom. (Index participant; HIV-uninfected; 20 years)

He would ask me if I do not trust him, why do I want to use condoms? And I would say, "No, I need to protect myself from HIV and pregnancy because I am still in school." I think he was doing his thing, because we would have sex and he would show me as he is putting it on, and then we would have sex, but I would feel his sperms which means the condom is not there and I would find it in between my thighs. Maybe he would take it off when I was not paying attention. That is how I got pregnant. (Index participant; HIV-uninfected; 19 years)

\section{Peer and Community Factors: Township Environment, Lack of Meaningful Daily Activities, and Social Isolation}

Several concerns related to the community in which these young women grew up were raised. The first, raised by all healthcare providers and slightly more than half of focus group participants, involved the township environment, which, in addition to having a high prevalence of HIV, was described as crowded, unsanitary, and in some cases, unsafe, with little adult oversight. The environment was viewed as a challenging place to raise a child, where violence was prevalent, and young children were exposed to crime and adult sexuality; one participant highlighted not only childhood exposure to adult sexuality as problematic, 
but witnessing women as subservient to men with respect to sexual behavior as well:

You find that there are people who live in small rooms and they share a bedroom with children. When a person wants sex and is eager for it...you forget that you have children here, especially the fathers. The mothers, most of the time want the fathers to do things for us and are not independent, so when the father says he wants this, you give it to him and you find that they will have sex here and the child is watching and is asking themselves 'what is going on?' (Administrative Support staff for an NGO; female; 43 years)

Another factor reported to influence adolescent development was how young women spent their time. Participants across all three groups reported that young women have no structured activities (e.g., participation in community- or school-based activities) and a limited repertoire of daily activities. Some index participants had only completed primary school (see Table 1), but were precluded from advancing their education due to competing demands, such as pregnancy, childcare (both for their own as well as family member's children), wishes or demands of the extended family, or financial barriers. Other index participants were expected to work informally within the home in order to ensure they had a place to live, such as in the case of young women who had been orphaned with no alternative but to live with extended family members. These activities were unrelated to the educational, occupational, or personal advancement of the participants, and also took up enough time that it sometimes was not possible for the participant to attend school. Resulting free time was generally spent in unstructured ways, and in activities that hold little opportunity for pleasure or mastery, such as watching television, sleeping, or waiting to see their romantic partners. Participants also explained that there were few opportunities available for young women to engage in activities in the community. Thus, there are interconnections between familial factors (e.g., orphanhood, family input on how time is spent) and community factors (e.g., lack of opportunity to engage in structured activities).

If I am not watching the TV, I love to sleep. Those are the two things I spend my time doing. Maybe sometimes I would touch some chores in the house...there is nothing you can do in my community that you can involve yourself in, because even in church, there are no choirs, there is no such thing. (Index participant; HIV-uninfected; 18 years)

I just sit at home. There is nothing that I do, I just sit at home with my siblings and that is all. I wake up... and clean the house... and then I take a bath and fetch my mother's child from crèche. That is all, except when I have to come to the clinic. (Index participant; HIV-uninfected; 18 years)
A third factor was a high degree of social isolation and a lack of same-sex peer relationships. Less than one-third of index participants reported the presence of any friends; their social interactions were related to family members, many of which were described negatively, and their romantic partners, some of which were also described as negative. This sometimes resulted in an idealization of and a reliance on the romantic partner relationship (discussed in greater detail under relational barriers).

Friends are backstabbers. I do not discuss my business with them. And the neighbors get happy when they learn something bad about you. I do not tell them anything. I don't like to sit with friends most of the time. (Index participant; HIV-uninfected; 19 years)

I don't know whether stepmothers are all like that but I don't get along with my stepmother. Since she came along everything changed. I don't get nothing at home...so if ever I need something I get it from him [boyfriend]. (Index participant; HIV-infected; 20 years)

The one that is most important at the moment is my relationship with my baby's father...I see the way he takes care of me. Even when there is no food at home, he would bring food. He does not judge me; he helps a lot because he understands the situation. (Index participant; HIVuninfected; 18 years)

\section{Societal: Far-Reaching Impact of Stigma, and the Role of Poverty}

Stigma emerged as a prominent barrier to effectively managing HIV risk from the perspective of all participants, both in terms of talking about and testing for HIV. Index participants highlighted that fear of losing social support (often from their romantic partners) drives lack of disclosure, which fuels transmission.

It [HIV] is increasing because people have secrets; people hide and do not tell their partners that it's like this and that he is HIV ... and another gets infected like that. And that person will also be scared to tell another one, then they will continue infecting each other. (Index participant; HIV-infected; 18 years)

For some, it is hard to disclose to their partner and you have to live with the secret without telling your partner because some of them are scared to lose their partner... The reality is that most of the guys want sex without a condom, so they just run away if you disclose. So HIV positive people have that pressure of taking the treatment, disclosing these things to their partners because some of their partners do not understand about HIV/AIDS and 
because some of them do not come and get tested, it is only the women. (Student Nurse; female; 23 years)

Poverty and unemployment were also referenced as barriers to effective HIV prevention. A small number of index participants and slightly more than half of the healthcare providers cited a lack of available and accessible jobs leading to unemployment or underemployment and too much unstructured time. All participants also discussed the role of material needs and desires in increasing young women's risk of HIV in the context of too few financial resources. Specifically, participants discussed young women's desires for material possessions such as cell phones, alcohol and clothes, and even more basic needs, such as food. As noted in relational characteristics, when young women value and desire these things but cannot buy them, it opens the door to relationships that may be driven by economic need, placing women at greater risk of HIV acquisition. Male partners in these economically motivated relationships were described as older, and often having a profession that allowed for frequent travel, such as bus/taxi drivers.

Because as they are not working, we like styles too much... so they are people who can provide, and we thinking like having sex, you see, you can get money to buy something so that when I go out with my friend I will dress smart. (Index participant; HIV-infected; 19 years)

Some people know how to sleep with another person, just because at their home they don't have anything to eat, they don't have anything, just to earn some money so they can support some members of their families with that money that they are receiving. (Index participant; HIV-infected; 19 years)

The children get into temptation because maybe there is no food at home and she would just go around and get tempted by dating older men and have sex with them because she wants to get money to buy food, and she will come with this food at home that she had by having sex with an older man, a sugar daddy, so that they can eat at home, and after that, she gets infected with HIV and gets sick. (Home Health Aide; female; 39 years)

\section{Discussion}

The current study explored factors that contribute to HIV risk among young, pregnant women living in KwaZulu-Natal, South Africa. Findings suggest most young women possess a fair amount of HIV-related knowledge, and many have first-hand experience with HIV, with over one-third being HIV-infected, and also often in the form of an ill family or community member. However, a number of difficult, complex, and contextually specific circumstances impacting the lives of these women were described.
These circumstances likely interact with one another and lay the foundation for HIV risk in this population. These circumstances include factors such as social isolation, poverty, and a limited repertoire of daily activities, mainly fueled by lack of available community activities, difficulties with school completion, and underemployment. Despite being a "second generation" of individuals affected, severely, by HIV in SA, these young women also spoke about challenges related to HIV prevention, including a sense of "invincibility" and fearlessness around HIV, as well as partner-related barriers to condom use (Tables 4, 5).

While some of the concepts described in the study have been associated with HIV risk among young women before (e.g., challenges with condom use and orphanhood), some more novel risk factors emerged as well. For example, there is some evidence of evolving attitudes toward HIV infection in the data, specifically, that HIV is no longer something to fear. There was also some evidence of potential HIV prevention fatigue, though it is difficult to parse out true HIV prevention fatigue from normal adolescent perceived "invulnerability" (Anderson, Beutel, \& MaughanBrown, 2007). Providers talked about young people "closing their ears" to messages of HIV prevention. It is notable that attitudes of invincibility persist even after witnessing personal, negative consequences of HIV. When queried about how healthcare providers could help young women remain HIV negative, many participants across all three groups expressed feelings of hopelessness, noting that nothing further could be done.

While the design of the study and sample size of the study cannot support conclusions about the relationships between concurrent partnerships and age, the absence of certain findings as assessed by our demographic data and interview data is also notable. For example, while some reports have cited concurrent partnerships (Chen et al., 2007) as a driver of risk, this was not evident among the index participants, nor were significant age gaps between index participants and their partners routinely identified (see Table 1), which has historically been understood to confer HIV risk to young women. A more recent study demonstrated that differences did not exist in rates of HIV transmission among women with younger versus older partners (Harling et al., 2014). In addition, while healthcare providers and community members referenced substance use as a risk of HIV among young women, index participants did not endorse individual substance use as a problem (though acknowledged its use among others as problematic), nor did they discuss forced sex. Lack of HIV-related knowledge was also not evident in this sample.

It is important to think about the ways in which these described risk factors may interact with and influence one another. Taken together, we have an understanding of the dire circumstances surrounding these young women. This constellation of risk - poverty, lack of meaningful adult relationships and friendships, perceived lack of future opportunity - may help us understand some of the decisions around sexual health described by the participants. In many cases, the young women described an ideal- 
Table 4 Sample study content areas and sample questions/probes for index participants

\begin{tabular}{|c|c|}
\hline Content area & Sample questions and probes \\
\hline $\begin{array}{l}\text { Community involvement and } \\
\text { relationships with caregivers }\end{array}$ & $\begin{array}{l}\text { I am interested in hearing what is going on in your life right now. How do you occupy your time? (probes for } \\
\text { school enrollment/completion status, employment status) } \\
\text { Who do you live with? (probes for history of living arrangements, nature of relationships with guardians, } \\
\text { number of people in the home) }\end{array}$ \\
\hline Relationships (general) & $\begin{array}{l}\text { What are your most important relationships? (probes for defining what makes a relationship important and } \\
\text { nature of the relationships) } \\
\text { Who else do you spend time with? }\end{array}$ \\
\hline Relationships (sexual) & $\begin{array}{l}\text { Please tell me about your relationship with the baby's father } \\
\text { Do you have any other partners right now? Tell me about those relationships (probes for length of } \\
\text { relationship, how serious the relationship is/defining serious intimate relationships, sexual behavior } \\
\text { within the relationship) }\end{array}$ \\
\hline HIV: impact, attitudes and risk behaviors & $\begin{array}{l}\text { Please tell me about the ways in which HIV has affected your life (probes for HIV-related loss, financial } \\
\text { impact, exposure to trauma, impact on ability to form relationships with others) } \\
\text { Sometimes very big problems such as HIV can feel overwhelming. Sometimes when people feel } \\
\text { overwhelmed, they give up trying to solve a problem... other people may feel more hopeful about HIV } \\
\text { because of new research and availability of medicine to treat HIV. How do you feel? (probes for } \\
\text { knowledge of biomedical prevention efforts) } \\
\text { How do you think HIV will affect your future? } \\
\text { Tell me about the things that impact your sexual behavior or decisions around having sex (probes for } \\
\text { partner factors and substance use) } \\
\text { What do/did you do in your life/relationships to protect yourself from HIV? } \\
\text { We've talked about some HIV prevention strategies... how possible is it for you to do these things in your } \\
\text { own life? }\end{array}$ \\
\hline Content of potential intervention & $\begin{array}{l}\text { What, if anything, could have/could help you stay HIV negative? } \\
\text { Who else (besides young women) need to be involved in an HIV prevention program for young women? } \\
\text { Other than HIV, what are the big problems facing young girls like yourself in Umlazi? } \\
\text { There are many strategies that healthcare providers could use to help young women stay HIV negative... } \\
\text { what approach do you think would be most effective? }\end{array}$ \\
\hline
\end{tabular}

ization of (and in some cases a dependence on) their romantic partner, who was often able to meet basic needs (such as in the provision of food), gifts, emotional support, and a social activity that the young women were able to look forward to. Therefore, it is understandable that despite knowledge of risk (from both formal education and personal experience), these young women often abandon attempts at condom negotiation when their partners express displeasure, or fail to "adequately" speak with their partners about HIV, particularly in the context of feeling invincible or hopeless around HIV. We have proposed and presented results according to a model on how these risk factors may interact based on our findings (see Fig. 1).

Thus, our findings underscore how personal, contextual, and societal factors may jointly contribute to young women's engagement in partnerships within which they hold limited power to advocate for safer sex practices. These partnership dynamics in turn predispose women to risky sexual behavior and increased vulnerability to acquiring HIV. This conceptualization is consistent with a theoretical model of HIV risk that focuses on the effect of gender and relationship power inequity on HIV acquisition among young women in South Africa (Jewkes et al., 2010). Jewkes et al. postulated that gender and relationship power inequity, in confluence with interrelated psychosocial factors and societally ascribed gender norms, may contribute to risky sexual behaviors and HIV risk. However, this model does not account for additional factors such as lack of meaningful social relationships, perceived invincibility, and lack of community resources, which our study has found may also influence young South African women's sexual health behaviors. Taken together, our findings both highlight the value of a gender inequitiesbased model of HIV risk, as well as the need to broaden such a model to include other salient personal, social, and community factors as encompassed by a socioecological framework.

Interventions developed for use with youth in sub-Saharan Africa have shown some success on some markers of HIV risk (e.g., condom use, HIV/AIDS knowledge, HIV testing, number of casual partners) in clinical trial settings (Napierala Mavedzenge et al., 2011), but population rates of both pregnancy and HIV remain relatively stable (SANAC, 2012; Statistics South Africa, 2012). When considering implementation of effective HIV prevention interventions from the clinical trial setting into communities, it may be important to think about the multidimensional challenges to HIV prevention described in this sample, and how interventions might be used together, or modified, to target 
Table 5 Sample study content areas and sample questions/probes for health care providers and community stakeholders

\begin{tabular}{|c|c|}
\hline Content area & Sample questions and probes \\
\hline Background information & $\begin{array}{l}\text { I would like to start off by asking you to tell me a little bit about your role in the community } \\
\text { Please tell me about your experiences working with women ages } 16-19 \text {, particularly in Umlazi }\end{array}$ \\
\hline $\begin{array}{l}\text { Challenges faced by young } \\
\text { women (general) }\end{array}$ & $\begin{array}{l}\text { What are some of the challenges faced by young women, particularly those in Umlazi, today? (probes for } \\
\text { orphanhood, poverty, violence, unplanned/teenage pregnancy) } \\
\text { What are the causes of some of these problems? }\end{array}$ \\
\hline Challenges to HIV prevention & $\begin{array}{l}\text { You have mentioned several challenges faced by young women in Umlazi today... How do these challenges affect } \\
\text { young women's risk for becoming infected HIV? } \\
\text { As you know, there are many factors that affect the nature of sexual relationships. What have you noticed about } \\
\text { young women's relationships that may contribute to especially high HIV rates? (probes for what/who has the } \\
\text { most influence on young women's sexual behavior, power of women in these relationships, condom } \\
\text { negotiation) } \\
\text { Some of the young women we have spoken with have mentioned social gatherings known as inkwari. Tell me what } \\
\text { you have heard about these gatherings (probes for description of substance use) }\end{array}$ \\
\hline Content of potential intervention & $\begin{array}{l}\text { Please tell me about some of the things your community is currently doing to help young women remain HIV } \\
\text { negative (probe for what strategies work best and do not work, what could help you to do your job better, what is } \\
\text { not currently done that could make a difference) } \\
\text { Who else (besides young women) need to be involved in an HIV prevention program for young women? } \\
\text { There are many strategies that healthcare providers could use to help young women stay HIV negative... what } \\
\text { approach do you think would be most effective? } \\
\text { What things may make it hard for young women to benefit from a program designed to reduce the risk of HIV } \\
\text { infection? }\end{array}$ \\
\hline
\end{tabular}

The focus group and key informant interviews shared many common questions; therefore, we grouped them together

layered risk behavior. One-dimensional approaches are unlikely to have long-term effectiveness. For example, structural interventions may target some aspects of poverty, while condom negotiation skills trainings address the potential for relational barriers. However, neither strategy addresses the factors that may make one unable to use those strategies regularly as described here, such as the need for intimacy, social support, meaningful daily activities and sometimes even basic needs, such as food. The importance of involving and targeting young men in intervention development cannot be overstated. A systematic review of gender transformative interventions concludes that such interventions can be effective in altering behaviors associated with HIV risk, such as intimate partner violence and condom use (Dworkin, Treves-Kagan, \& Lippman, 2013). It is worth noting that none of the index participants' pregnancies were planned; optimal care for this population will involve programs that address both HIV prevention and family planning simultaneously (Crankshaw, Smit, \& Beksinska, 2016).

Today's young South African women are living in an HIV hyperendemic setting in which there are no ideal HIV prevention strategies available. Moreover, these women are at high risk of unplanned pregnancy, which may have negative consequences for infant health, such as in the case of vertical transmission of HIV. Faced with poverty and social isolation, many young women seek stability in relationships with male partners. Meanwhile, the prevalence of multiple sexual partnerships among South African men continues to rise, even as condom usage declines (Shisana et al., 2014). As evidenced by our interviews, although women rely on their partners for resources and social support, they cannot always rely on their partners to complete HIV testing, disclose their status, or use condoms. Consequently, there is no "silver bullet" to solve the continued problem of elevated rates of HIV infection in this population.

During the time this study was conducted, advances in biomedical prevention (such as pre-exposure prophylaxis, or PrEP) have occurred. While this may confer additional support for HIV protection for young women who are otherwise disempowered with respect to their own sexual health, PrEP studies conducted among African women have not always shown the same level of success as studies with other populations, such as men who have sex with men (Grant et al., 2010) and serodiscordant couples (Baeten et al., 2012). However, given the complicated and multifaceted factors that confer HIV risk and that condom use is decreasing (Shisana et al., 2014), PrEP may be a key element of multidimensional prevention approaches. While adherence is necessary for these tools to work effectively, systemic and topical PrEP strategies allow women to take better direct control of their risk, and their successful use may depend less on male partner preferences. Available data on the use of biomedical prevention strategies among women in Africa is complicated (Marazzo et al., 2013; Van Damme et al., 2012; van der Straten, Van Damme, Haberer, $\&$ Bangsberg, 2012), but suggests they are highly effective in populations that are able to adhere. Research is urgently needed to understand how we can support the use of PrEP as part of HIV prevention packages among high-risk young women, as 
PrEP has the potential to transcend the some of the relational barriers observed to negatively impact HIV prevention efforts.

This study had some strengths as well as limitations. A large sample size and sampling participants with multiple perspectives allowed for in-depth data collection and triangulation of data among participants; accessioning data from men would have further strengthened the findings. However, women younger than 18 years of age are also at heightened risk of HIV; none of those women were included in this sample. Sampling pregnant women only may have also biased the sample toward women engaging in unprotected sex, and we are unable to comment on same age women without pregnancy (who may not necessarily be engaging in unprotected sex) from these data. Furthermore, the experience of pregnancy may have amplified participants' dependence on their romantic partners. Because we sampled participants across a wide variety of topics, we may have failed to achieve adequate depth of data on certain domains. The absence of some established risk factors in the data (e.g., alcohol use and concurrent partnerships) does not necessarily mean that they do not occur or influence risk; the study was not designed to address such epidemiological questions. Furthermore, HIV status was self-reported. Despite these limitations, this study provides an up-to-date picture of factors influencing HIV acquisition in a particularly high-risk population and provides a framework for thinking about the future of HIV prevention interventions among young women.

Acknowledgements This project was funded by the Mark and Lisa Schwartz Family Foundation, the National Institute of Mental Health (NIMH) R03 MH093237. Dr. Psaros' time was also supported K23 MH096651. Additional author time was supported by K23 MH095655 (Matthews), K24 MH094214 (Safren), and K24 MH087227 (Bangsberg), and R24 HD077976 (Harrison). The authors thank the participants for sharing their knowledge.

\section{Compliance with Ethical Standards}

Conflict of interest Psaros, Milford, Smit, Greener, Mosery, Matthews, Harrison, Gordon, Mimiaga, Bangsberg declare that they have no conflict of interest. Dr. Safren has published books and materials about Cognitive Behavioral Therapy with Oxford University Press, Guilford Publications, and Springer.

Ethical Approval All procedures performed in studies involving human participants were in accordance with the ethical standards of the institutional and/or national research committee and with the 1964 Declaration of Helsinki and its later amendments or comparable ethical standards.

Informed Consent Informed consent was obtained from all individual participants included in the study.

\section{References}

Anderson, K. G., Beutel, A. M., \& Maughan-Brown, B. (2007). HIV risk perceptions and first sexual intercourse among youth in Cape Town South Africa. International Family Planning Perspectives, 33, 98-105. doi:10.1363/ifpp.33.098.07.
Baeten, J. M., Donnell, D., Ndase, P., Mugo, N. R., Campbell, J. D., Wangisi, J., ... Partners PrEP Study Team. (2012). Antiretroviral prophylaxis for HIV prevention in heterosexual men and women. New England Journal of Medicine, 367, 399-410. doi:10.1056/NEJMoa1108524.

Baeten, J. M., Palanee-Phillips, T., Brown, E. R., Schwartz, K., Soto-Torres, L. E., Govender, V., ... MTN-020-ASPIRE Study Team. (2016). Use of a vaginal ring containing dapivirine for HIV-1 prevention in women. New England Journal of Medicine, 375, 2121-2132. doi:10.1056/ NEJMoa1506110.

Browne, F. A., \& Wechsberg, W. M. (2010). The intersecting risks of substance use and HIV risk among substance-using South African men and women. Current Opinion in Psychiatry, 23, 205-209. doi:10.1097/ YCO.0b013e32833864eb.

Chen, L., Jha, P., Stirling, B., Sgaier, S. K., Daid, T., Kaul, R., ... International Studies of HIV/AIDS (ISHA) Investigators. (2007). Sexual risk factors for HIV infection in early and advanced HIV epidemics in Sub-Saharan Africa: Systematic overview of 68 epidemiological studies. PLoS ONE, 2, e1001. doi:10.1371/journal.pone.0001001.

Chirinda, W., \& Peltzer, K. (2014). Correlates of inconsistent condom use among youth aged 18-24 years in South Africa. Journal of Child and Adolescent Mental Health, 26, 75-82. doi:10.2989/17280583.2013. 877912.

Crankshaw, T. L., Smit, J. A., \& Beksinska, M. E. (2016). Placing contraception at the centre of the HIV prevention agenda. African Journal of AIDS Research, 15, 157-162. doi:10.2989/16085906.2016. 1204330.

DiClemente, R. J., Salazar, L. F., Crosby, R. A., \& Rosenthal, S. L. (2005). Prevention and control of sexually transmitted infections among adolescents: the importance of a socio-ecological perspective-A commentary. Public Health, 119, 825-836. doi:10.1016/j.puhe.2004. 10.015 .

Dietrich, J., Sikkema, K., Otwombe, K. N., Sanchez, A., Nkala, B., de Bruyn, G., ... Gray, G. E. (2013). Multiple levels of influence in predicting sexual activity and condom use among adolescents in Soweto, Johannesburg, South Africa. Journal of HIV/AIDS \& Social Services, 12, 404-423. doi:10.1080/15381501.2013.819312.

Dworkin, S. L., Treves-Kagan, S., \& Lippman, S. A. (2013). Gendertransformative interventions to reduce HIV risks and violence with heterosexually-active men: A review of the global evidence. AIDS and Behavior, 17, 2845-2863. doi:10.1007/s10461-013-0565-2.

Grant, R. M., Lama, J. R., Anderson, P. L., McMahan, V., Liu, A. Y., Vargas, L., ... iPrEx Study Team. (2010). Preexposure chemoprophylaxis for HIV prevention in men who have sex with men. New England Journal of Medicine, 363, 2587-2599. doi:10.1056/NEJMoa1011205.

Gregson, S., Mushati, P., Grusin, H., Nhamo, M., Schumacher, C., Skovdal, M., ... Campbell, C. (2011). Social capital and women's reduced vulnerability to HIV infection in rural Zimbabwe. Population and Development Review, 37, 333-359.

Harling, G., Newell, M.-L., Tanser, F., Kawachi, I., Subramanian, S., \& Barnighausen, T. (2014). Age-disparate relationships and HIV incidence amongst rural South Africa women. Presented at the Conference on Retroviruses and Opportunistic Infections, Boston, MA.

Harrison, A., Newell, M.-L., Imrie, J., \& Hoddinott, G. (2010). HIV prevention for South African youth: Which interventions work? A systematic review of current evidence. BMC Public Health, 10, 102. doi: 10.1186/1471-2458-10-102.

Hilber, A. M., Francis, S. C., Chersich, M., Scott, P., Redmond, S., Bender, N., ... Low, N. (2010). Intravaginal practices, vaginal infections and HIV acquisition: Systematic review and meta-analysis. PLOSONE, 5, e9119. doi:10.1371/journal.pone.0009119.

Hoffman, S., O'Sullivan, L. F., Harrison, A., Dolezal, C., \& Monroe-Wise, A. (2006). HIV risk behaviors and the context of sexual coercion in young adults' sexual interactions: Results from a diary study in rural South Africa. Sexually Transmitted Diseases, 33, 52-58.

Huberman, M., \& Miles, M. B. (2002). The qualitative researcher's companion. Beverly Hills, CA: Sage. 
Jewkes, R. K., Dunkle, K., Nduna, M., \& Shai, N. (2010). Intimate partner violence, relationship power inequity, and incidence of HIV infection in young women in South Africa: A cohort study. Lancet, 376, 41-48. doi:10.1016/S0140-6736(10)60548-X.

Jewkes, R., \& Morrell, R. (2010). Gender and sexuality: Emerging perspectives from the heterosexual epidemic in South Africa and implications for HIV risk and prevention. Journal of the International AIDS Society, 13, 6. doi:10.1186/1758-2652-13-6.

Kalichman, S. C., Simbayi, L. C., Kagee, A., Toefy, Y., Jooste, S., Cain, D., \& Cherry, C. (2006). Associations of poverty, substance use, and HIV transmission risk behaviors in three South African communities. Social Science and Medicine, 62, 1641-1649. doi:10.1016/j.socscimed.2005. 08.021.

Kapiga, S., Bekker, L.-G., Devlin, B., Borremans, M., Rosenberg, Z., \& IPM 027/The Ring Study Research Center Teams. (2016). Safety and efficacy of dapivirine vaginal ring for HIV-1 prevention in African women. Presented at the Conference on Retroviruses and Opportunistic Infections. Retrieved from http://www.croiconference.org/sessions/safetyand-efficacy-dapivirine-vaginal-ring-hiv-1-prevention-african-women.

Marazzo, J., Birbeck, G., Nair, G., Palanee, T., Mkhize, B., Nakabiito, C., ... Chirenje, M. (2013). Pre-exposure prophylaxis for HIV in women: Daily oral tenofovir, oral tenofovir/emtricitabine or vaginal tenofovir gel in the VOICE study. Presented at the Conference on Retroviruses and Opportunistic Infections, Atlanta, GA.

Miles, M. B., \& Huberman, A. M. (1984). Qualitative data analysis: A sourcebook of new methods. Beverly Hills, CA: Sage Publications.

Mugo, N. R., Heffron, R., Donnell, D., Wald, A., Were, E. O., Rees, H., ... Baeten, J. M. (2011). Increased risk of HIV-1 transmission in pregnancy: A prospective study among African HIV-1 serodiscordant couples. AIDS, 25, 1887-1895. doi:10.1097/QAD.0b013e32834a9338.

Napierala Mavedzenge, S. M., Doyle, A. M., \& Ross, D. A. (2011). HIV prevention in young people in sub-Saharan Africa: A systematic review. Journal of Adolescent Health, 49, 568-586. doi:10.1016/j.jadohealth. 2011.02.007.

National Department of Health. (2011). The national antenatal sentinel HIV and syphilis prevalence survey South Africa 2011. Retrieved from http://www.health-e.org.za/wp-content/uploads/2013/05/f0980fb5107 a7ce543a8bd5730e52333.pdf.

Nyembezi, A., Resnicow, K., Ruiter, R. A. C., van den Borne, B., Sifunda, S., Funani, I., \& Reddy, P. (2014). The association between ethnic identity and condom use among young men in the Eastern Cape Province, South Africa. Archives of Sexual Behavior, 43, 1097-1103. doi:10.1007/ s10508-014-0307-1.

Operario, D., Pettifor, A., Cluver, L., MacPhail, C., \& Rees, H. (2007). Prevalence of parental death among young people in South Africa and risk for HIV infection. Journal of Acquired Immune Deficiency Syndromes, 44, 93-98. doi:10.1097/01.qai.0000243126.75153.3c.

Pettifor, A., O’Brien, K., Macphail, C., Miller, W. C., \& Rees, H. (2009). Early coital debut and associated HIV risk factors among young women and men in South Africa. International Perspectives on Sexual and Reproductive Health, 35, 82-90. doi:10.1363/ifpp.35.082.09.

Pettifor, A. E., Rees, H. V., Kleinschmidt, I., Steffenson, A. E., MacPhail, C., Hlongwa-Madikizela, L., ... Padian, N. S. (2005). Young people's sexual health in South Africa: HIV prevalence and sexual behaviors from a nationally representative household survey. AIDS, 19, 15251534.

Pettifor, A. E., Rees, H., Steffenson, A. E., Hlongwa-Madikizela, L., MacPhail, C., Vermaak, K., \& Kleinschmidt, I. (2004). HIV and sexual behaviour among young South Africans: A national survey of 1524 year olds. Johannesburg: Reproductive Health Research Unit, University of the Witwatersrand.

Pitpitan, E. V., Kalichman, S. C., Eaton, L. A., Cain, D., Sikkema, K. J., Watt, M. H., ... Pieterse, D. (2013). Co-occurring psychosocial problems and HIV risk among women attending drinking venues in a South African township: A syndemic approach. Annals of Behavioral Medicine, 45, 153-162. doi:10.1007/s12160-012-9420-3.

Registrar of Medicines. (2015). Medicines Control Council approves fixeddose combination of tenofovir disoproxyl fumarate and emtricitabine for pre-exposure prophylaxis of HIV (Press Release). Retrieved from http://www.mccza.com/documents/2e4b3a5310.11_Media_release_ ARV_FDC_PrEP_Nov15_v1.pdf.

SANAC. (2012). South Africa GlobalAIDS Response Progress Report 2012. Retrieved from http://www.unaids.org/en/dataanalysis/knowyourresp onse/countryprogressreports/2012countries/ce_ZA_Narrative_Report. pdf.

Shisana, O., Rehle, T., Simbayi, L. C., Zuma, K., Jooste, S., Zungu, N., ... Onoya, D. (2014). South African national HIV prevalence, incidence and behaviour survey, 2012. Cape Town: HRSC Press.

Statistics South Africa. (2012). General Household Survey 2011. Retrieved from https://www.statssa.gov.za/publications/P0318/P0318April2012. pdf.

Stokols, D. (1996). Translating social ecological theory into guidelines for community health promotion. American Journal of Health Promotion, 10, 282-298.

Strauss, A., \& Corbin, J. (1998). Basics of qualitative research: Procedures and techniques for developing grounded theory. Thousand Oaks, CA: Sage.

Toska, E., Cluver, L. D., Boyes, M., Pantelic, M., \& Kuo, C. (2015). From "sugar daddies" to "sugar babies": Exploring a pathway among agedisparate sexual relationships, condom use and adolescent pregnancy in South Africa. Sexual Health, 12, 59-66. doi:10.1071/SH14089.

UNAIDS. (2013). Global report: UNAIDS report on the global AIDS epidemic 2013. Retrieved from http://www.unaids.org/en/media/unaids/ contentassets/documents/epidemiology/2013/gr2013/UNAIDS_ Global_Report_2013_en.pdf.

Van Damme, L., Corneli, A., Ahmed, K., Agot, K., Lombaard, J., Kapiga, S., ... FEM-PrEP Study Group. (2012). Preexposure prophylaxis for HIV infection among African women. New England Journal of Medicine, 367, 411-422. doi:10.1056/NEJMoa1202614.

van der Straten, A., Van Damme, L., Haberer, J. E., \& Bangsberg, D. R. (2012). Unraveling the divergent results of pre-exposure prophylaxis trials for HIV prevention. AIDS, 26, F13-F19. doi:10.1097/QAD. 0b013e3283522272.

Wild, L. G., Flisher, A. J., Bhana, A., \& Lombard, C. (2004). Associations among adolescent risk behaviours and self-esteem in six domains. Journal of Child Psychology and Psychiatry, 45, 1454-1467. doi:10. 1111/j.1469-7610.2004.00851.x. 